\title{
Humans are Underrated: Art and Labor after Amazon
}

\author{
JOHANNA GOSSE \\ Executive Editor, Media- $N$
}

This special issue of Media- $N$ gathers perspectives on artistic labor in an increasingly automated global economy, focusing on the impact of artificial intelligence and the role of Amazon.com, Inc. in reshaping how work is defined, valued, and performed. Our contributors are artists, curators, scholars, and critics interested in labor value, emerging forms of exploitation and alienation, as well as new possibilities for collective resistance, solidarity, and critique.

The issue borrows its title from the managerial self-help bestseller, Geoff Colvin's Humans are Underrated: What High Achievers Know That Brilliant Machines Never Will, which advocates for businesses to prioritize and reward uniquely "human" qualities as a strategic response to the automation of existing jobs and industries. ${ }^{1}$ Such "underrated" forms of human labor encompass storytelling, improvisation, spontaneity, imagination, critical judgment, taste, empathy, authenticity, sincerity, attention, intimacy, care, cheer, and humor. Often referred to as "soft skills," these behaviors and capacities are often considered as evidence of individuality and authenticity, and, not coincidentally, also as hallmarks of aesthetic expression and appreciation. As such, the "humans are underrated" managerial paradigm inadvertently positions the figure of the artist (or more aptly, the "creative entrepreneur") as the ideal model of a resilient, automationresistant employee.

As Rob Horning observes, this neoliberal instrumentalization of humanness defines individuality not as "a product of our snowflake souls but a production input shaped by the exigencies of the capitalist production process. 'Uniqueness' is simply what can't be otherwise automated but remains exploitable." By performing these supposedly unique human behaviors, the "high achievers" championed by Colvin are able to generate surplus value more effectively and convincingly than their machine counterparts - that is, for the time being. Yet, by negatively defining humanness in terms of what "brilliant machines" are not yet able to perform, or in Horning's words, what "remains exploitable," Colvin frames the question of what is uniquely human not in terms of what only humans can do, but of when machines will inevitably learn how to do it better-including art.

Art has long been regarded as the final frontier for automation, from Maillardet's "draughtsmanwriter" automaton at the turn of the 19th century, to Alan Turing's mid-20th century theorization 
of artificial intelligence. ${ }^{3}$ Marxist theorist Dave Beech helpfully clarifies the status of art vis-à-vis automation when he states that "Art is always produced by cyborgs." At a fundamental level, art necessitates human/machine assemblages - if only pigment or paintbrush — in order to transform the material world. Elaborating on his earlier claim that artistic production is a resolutely noncapitalist activity, ${ }^{5}$ Beech insists that attaching special value to uniquely "human" forms of labor represents a romantic, promethean, even aristocratic valorization of human creativity that obscures the fact that these "underrated" forms of work are equally vulnerable to exploitation as manual, waged labor. In an implicit challenge to Left Accelerationism's embrace of automation as intrinsically emancipatory, Beech asserts that "postcapitalism does not depend on another technological revolution... [and] does not mean the aestheticization of work or the unfettered use of automation for the purpose of releasing workers from work." ${ }^{\prime 6}$ Looking back to a year marked by widespread bourgeois revolutions and the publication of The Communist Manifesto, Beech reminds us that automation is nothing new, and "the promise of mechanization, automation, roboticisation, digitalization and $\mathrm{AI}$ is only as imminent now as it was in 1848."7

That said, the scope of automation in the early 21 st century presents specific challenges. Take Amazon.com, Inc., which currently ranks second to Walmart as the largest US-based corporate employer in the world, and is committed to deploying automation to invent new, more flexible forms of exploitation. The company's labor practices are subject to widespread criticism, from the unsafe conditions, long shifts, and low wages endured by its warehouse and delivery employees to the notoriously cutthroat culture of its corporate HQs. Far less visible or publicized is the international workforce employed through Amazon's online microlabor platform, Mechanical Turk (mTurk). Advertised as "an on-demand, scalable, human workforce to complete jobs that humans can do better than computers," mTurk is an online marketplace that enables individuals and companies to hire workers for "Human Intelligence Tasks" (HITs), simple assignments like filling out surveys, analyzing receipts, performing online research, transcribing audio, or providing photo captions. The vast majority of these HITs take less than a minute to complete and pay around five to ten cents, meaning that workers must complete hundreds, even thousands of HITs in order to earn basic subsistence wages. While most HITs are used for the purposes of marketing and industry research, in the aggregate, these tasks contribute to machine learning: companies, including Amazon itself, use mTurk data to train algorithms to perform tasks more like humans do. Thus, rather than AI, mTurk is AAI - artificial artificial intelligence that simulates algorithmic processes through invisible human labor. As independent contractors, mTurkers work remotely, often from home. They are isolated from one another and their employers, and only able to communicate via private message and message boards. And yet, despite its amorphous shape as a "workforce," this global proletariat is radically reshaping how labor is defined and organized, while also training the automated systems that will ultimately render their jobs obsolete.

mTurk is a recurring theme in the essays contained in this issue, which opens with a series of scholarly articles examining the relationship between contemporary art and automation. Kris Paulsen's essay traces the history of "Shitty Automation" back to 18th century automata, including 
the original chess-playing Mechanical Turk machine after which Amazon named its platform, and contemporary artistic engagement with the "shitty", dysfunctional, uncanny flipside of automation, including recent AI-generated paintings by Trevor Paglen. In her essay, "Regarding Artists Regarding Labor," curator Ana Torok considers recent works by Josh Kline, Andrew Norman Wilson, and Eva and Franco Mattes, artists who utilize strategies of performance and re-enactment to analyze and self-implicate artist and viewer within exploitative digital labor relations. Nathan Jones's essay considers the phenomenon of glitch poetics in algorithmically generated art works by Robbie Barrat, Juliana Huxtable, and the author's own collaborative project The Re-Reader, an artwork interface that scans and transforms pre-existing texts to generate "algorithmic, semantic, and aesthetic text performances." In glitch, Jones locates the potential for "machine misbehavior," a subversive method that suggests parallels to Paulsen's "shitty automation," and echoes Torok's interest in the critical possibilities opened up by engaging directly with automated systems.

The next section examines specific projects by artists who analyze the role of digital labor, automation, and Amazonification in daily life. Roger Beebe discusses his recent experimental essay film, Amazonia (2019), a work of desktop cinema that focuses on the impact of Amazon's labor practices on the American post-industrial landscape. As artists who engage directly with mTurk as "requesters," the research-based practices of Anxious to Make (collaborative duo Liat Berdugo and Emily Martinez), Zaneta Zukalova, and xtine burrough each examine the affective politics of the microlabor economy by foregrounding their own roles as participants in its exploitative relations. In "How AI Manufactures a Smile," scholar and poet Tung-Hui Hu interviews artist Elisa Giardina Papa about her practice in a wide-ranging conversation that touches upon questions of precarity, artificial intelligence, and affective computing. The issue concludes with Kris Cohen's review of the 2019 Seattle Art Fair, which until recently was financed by Microsoft co-founder Paul Allen. In analyzing the fair's public programming, Cohen identifies an opportunity to consider the intersection of affective labor and racial capitalism in the online subculture of autonomous sensory meridian response, or ASMR.

\footnotetext{
${ }^{1}$ Geoff Colvin, Humans Are Underrated: What High Achievers Know That Brilliant Machine Never Will (New York: Portfolio/Penguin, 2015).

${ }^{2}$ Rob Horning, "Do The Robot," The New Inquiry (August 12, 2015). Accessed March 18, 2020 at: https://thenewinquiry.com/blog/Do-The-Robot/.

${ }^{3}$ Turing quotes neurologist Geoffrey Jefferson: "Not until a machine can write a sonnet or compose a concerto because of thoughts and emotions felt, and not by the chance fall of symbols, could we agree that machine equals brain - that is, not only write it but know that it had written it." Alan Turing, "Computing Machinery and Intelligence," Mind: A Quarterly Review of Psychology and History (October 1950), 445.

${ }^{4}$ Dave Beech, Art and Postcapitalism: Aesthetic Labour, Automation and Value Production (London: Pluto Books, 2019), 64.

${ }^{5}$ Dave Beech, Art and Value: Art's Economic Exceptionalism in Classical, Neoclassical, and Marxist Economics (Leiden: Brill, 2015).

${ }^{6}$ Beech, 103.

7 Ibid.
} 